\title{
Design of Simply Supported Deep Beams Using Strut-and-Tie Models
}

\author{
by Adolfo B. Matamoros and Kuok Hong Wong
}

A procedure to calculate the amount of reinforcement and the strength of deep beams based on strut-and-tie models is presented. The proposed design equations were calibrated using experimental results from 175 simply supported beams found in the literature with a maximum shear span-to-depth ratio of 3 . The strength reduction coefficient for concrete in the main strut was found to decrease with the angle of inclination of the strut, resulting in lower values than those stated in Appendix A of the 2002 edition of the ACI 318 Building Code for beams with shear span-to-depth ratios greater than 1 .

Keywords: beam; shear; strut; tie

\section{INTRODUCTION}

The use of strut-and-tie models to determine the amount and distribution of reinforcement in concrete members entails a departure from the traditional approach to design. While engineers must abide by a basic set of guidelines in selecting the configuration of a strut-and-tie model, they are allowed to choose any model deemed suitable for the particular problem. The actual choice of strut-and-tie model is, in effect, intended to represent the path followed by internal forces within the structural element. The flexibility afforded by the method allows for the development of multiple solutions for the same problem. Consequently, sound engineering judgment and design experience are fundamental to achieve a safe and optimal solution.

Because several factors affect the amount and distribution of reinforcement in structural elements, understanding their behavior is essential for the selection of strut-and-tie models that lead to reasonable designs. The implications of using different strut-and-tie models for the design of deep beams are analyzed in reference to experimental results found in the literature.

\section{RESEARCH SIGNIFICANCE}

A set of equations to estimate the contribution of plain concrete to the total shear strength and the required amount of web reinforcement is developed based on simple strut-and-tie models representing the main load transfer mechanisms of deep beams. The strength reduction factor for the main strut is calculated and compared with values specified in the ACI (ACI Committee 318 2002) and AASHTO (1998) Codes. A simple expression for the strength reduction factor as a function of the angle of inclination of the strut is proposed.

\section{MECHANISMS OF SHEAR RESISTANCE IN DEEP BEAMS}

Two different mechanisms are commonly recognized (Aoyama 1993) as the principal mechanisms of shear resistance in deep beams with web reinforcement: 1) a truss mechanism, which is the main shear resistance mechanism in slender beams; and 2) an arch mechanism in which the load is transferred directly from the load point to the support. The fraction of the total shear resistance associated with each of the two mechanisms depends on several parameters, including the amount and distribution of reinforcement in the beam, compressive strength of the concrete, and the shear span-to-depth ratio.

Web reinforcement in deep beams generally consists of vertically and horizontally distributed reinforcement that is placed in various configurations. A number of different strut-and-tie models can be used for design, depending on the reinforcement configuration that is adopted and the shear span-to-depth ratio of the beam. Several models for the design of deep beams can be found in the literature (Rogowsky and MacGregor 1983; CEB-FIP 1990; Foster and Gilbert 1998).

\section{STRUT-AND-TIE MODELS USED TO CALCULATE STRENGTH OF DEEP BEAMS}

Results from four different strut-and-tie models representing basic load transfer mechanisms in deep beams were compared with experimental results from deep beams subjected to point loads. The analysis presented excludes beams in which the mode of failure was due to yielding of the main tension reinforcement. The first model (Fig. 1(b)) is the simplest because it neglects the contribution of web reinforcement to the strength of the beam. It consists of a direct strut between the load point and the support. A static analysis shows that the relationship between the applied load and the compressive force in the strut is given by

$$
F_{\text {strut }}=\frac{F}{\sin \theta}
$$

where $F$ is the force applied at the load point.

Two other simple mechanisms that account for the contribution of reinforcement to the total shear strength were investigated. In the first model, shear is carried by a truss in which the vertical tie (Element 4 in Fig. 1(c)) represents the vertical reinforcement. From statics, the force carried by the vertical tie is equal to the force applied at the load point.

$$
F_{\text {truss } 1}=F
$$

The third load transfer mechanism accounts for the forces carried by the horizontal reinforcement. In this case, shear is

ACI Structural Journal, V. 100, No. 6, November-December 2003

MS No. 02-140 received April 9, 2002, and reviewed under Institute publication policies. Copyright (C) 2003, American Concrete Institute. All rights reserved, including the making of copies unless permission is obtained from the copyright proprietors. Pertinent discussion including author's closure, if any, will be published in the SeptemberOctober 2004 ACI Structural Journal if the discussion is received by May 1, 2004. 
ACI member Adolfo B. Matamoros is an assistant professor in the Department of Civil, Environmental, and Architectural Engineering, University of Kansas, Lawrence, Kans. He received his $M S$ and $P h D$ from the University of Illinois at Urbana, Ill. He is Secretary of ACI Committee 408, Bond and Development of Reinforcement, and is a member of ACI Committees 341, Earthquake Resistant Concrete Bridges; 439, Steel Reinforcement; and Joint ACI-ASCE Committee 445, Shear and Torsion.

Kuok Hong Wong is a structural engineer at APEX Engineers, Downers Grove, Ill. He received his bachelor's and master's of science degrees at the University of Kansas.

transferred by the truss mechanism shown in Fig. 1(d), in which the horizontal member (Element 9) represents horizontal web reinforcement. Assuming that the angle of inclination of the strut is approximately equal to the arctangent of the shear spanto-depth ratio, the force in the horizontal tie is approximately

$$
F_{\text {truss } 2}=F \frac{a}{d}
$$

where ald is the shear span-to-depth ratio.

Figure 2 shows the variation of the force in the compressive strut, and horizontal and vertical truss elements with respect to the shear span-to-depth ratio calculated using Eq. (1) to (3). These forces correspond to the elastic forces in the respective elements, assuming that the total shear force is carried by each of the three mechanisms. Figure 2 shows that, according to Eq. (1), the force carried by the strut in the direct strut model (Fig. 1(b)) increases as the shear span-to-depth ratio increases. Similarly, Eq. (3) implies that the force in the horizontal element of the horizontal truss model (Element 9 in Fig. 1(d)) increases with a/d. Experimental observations show that both the force carried by the arch resistance mechanism (de Pavia and Siess 1965; Aoyama 1993) and the effect of the horizontal reinforcement (Rogowsky, MacGregor, and Ong 1986; Smith and Vantsiotis 1982; Warwick and Foster 1993) decrease with the shear span-to-depth ratio. Figure 2 illustrates that the results from simple truss models may not be consistent with experimentally observed behavior and may lead to reinforcement configurations that are not appropriate for the particular stress field. The CEB-FIP model code (CEB-FIP 1990) addresses this problem by suggesting that the total shear be distributed between different strut-and-tie models and by providing guidance about how to distribute the total force, depending on the shear span-to-depth ratio.

Element forces were calculated also using a fourth statically indeterminate strut-and-tie model that was a combination of the three models shown in Fig. 1. The support conditions were defined so that the overall truss would be statically determinate (Fig. 3).

The use of the stiffness method was necessary because the truss model is statically indeterminate internally. The stiffness coefficients were calculated based on the assumption that the modulus of elasticity and cross section area were constant and equal for all members. This assumption considerably simplified the modeling and analysis of the strut-and-tie model. The shear span-to-depth ratio was assumed equivalent to the cotangent of $\theta$, the angle of inclination of the strut. Figure 2 shows the fraction of the shear load acting on the vertical and the horizontal members of the statically indeterminate truss, for shear span-to-depth ratios ranging from 0 to 3 . As indicated by Fig. 2, the magnitude of both forces increased as the ald ratio increased.

Figure 2 shows that the interaction between mechanisms in the statically indeterminate truss model resulted in a significant reduction in the magnitude of the forces in the ties.

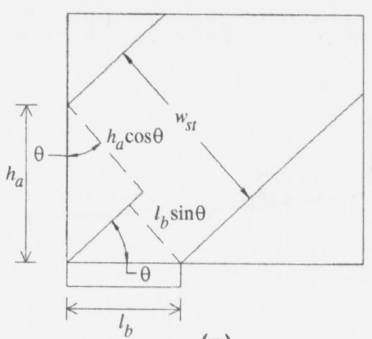

(a)

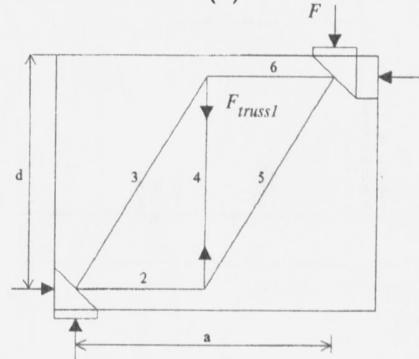

(c)

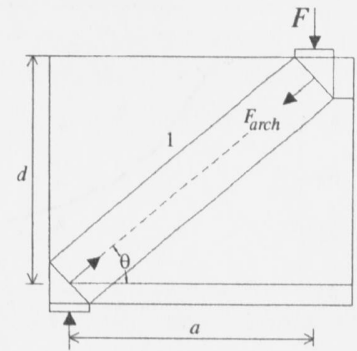

(b)

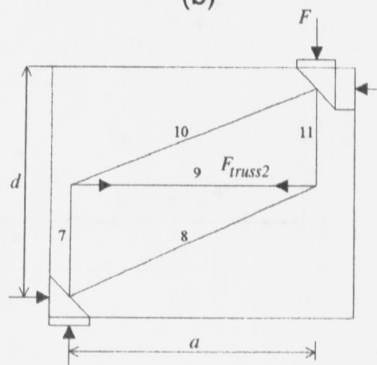

(d)
Fig. 1-(a) Dimensions of nodal zone; (b) compression strut mechanism; (c) vertical truss mechanism; and $(d)$ horizontal truss mechanism.

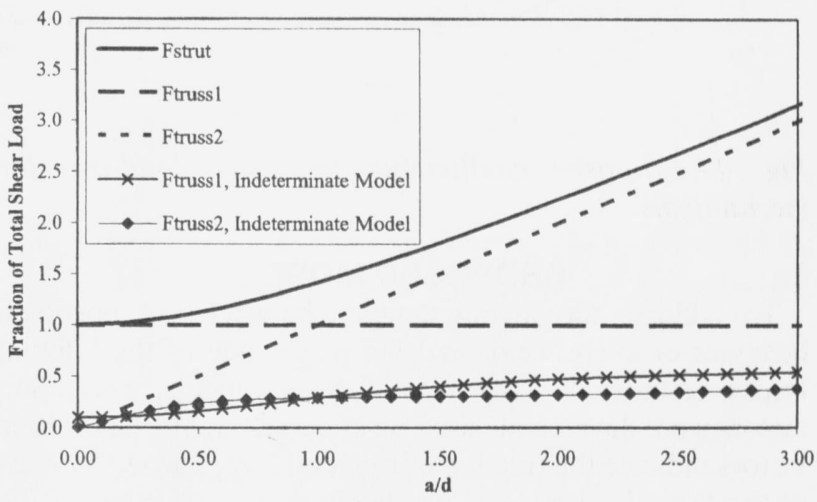

Fig. 2-Fraction of total shear load carried by truss elements in direct strut, horizontal truss, vertical truss, and statistically indeterminate truss models.
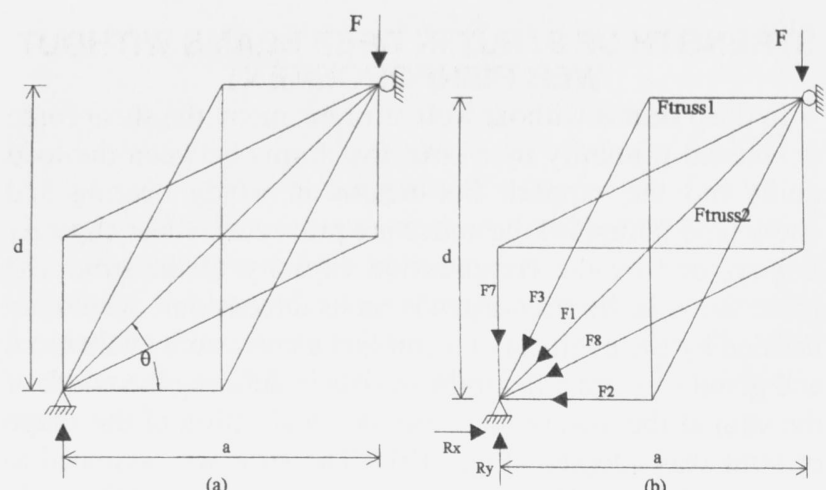

(b)

Fig. 3-Combined strut-and-tie model. 

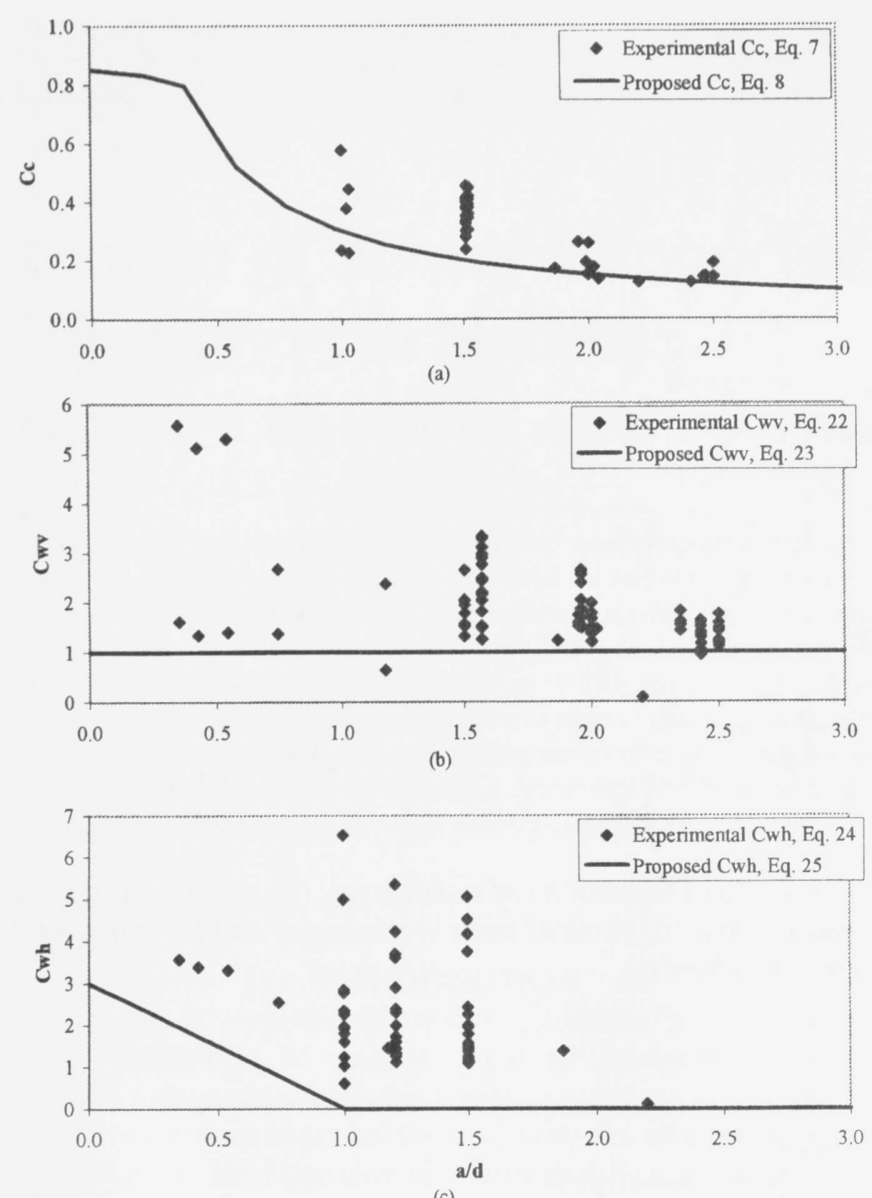

(c)

Fig. 4-Proposed coefficients for three load-transfer mechanisms.

\section{PROPOSED MODEL}

To address the inconsistencies between the observed behavior of deep beams and the magnitude of the internal forces calculated using elastic truss models, correction factors were developed based on experimental results. These factors indicate the fraction of the total force carried by each of the three load-transfer mechanisms as a function of the shear span-to-depth ratio. Each load-transfer mechanism is represented with a simple strut-and-tie model so design forces in ties and struts could be easily calculated using statics. The proposed methodology further simplified calculations by identifying key elements in each mechanism and establishing factors directly relating the nominal strength of those elements to the strength of the beam.

\section{STRENGTH OF STRUT IN DEEP BEAMS WITHOUT WEB REINFORCEMENT}

In deep beams without web reinforcement, the shear force is resisted primarily by a strut that forms between the load point and the support. For beams in which bearing and anchorage failures at the nodes are prevented, shear capacity is governed by the compressive capacity of the strut. The mean stress in the strut depends on its dimensions, which are defined by the engineer. To conduct a consistent evaluation, and given that some flexibility exists in defining the width of the strut at the load point, a simple idealization of the shape of strut was adopted (Fig. 1(b)). The strut was assumed to have a uniform width $w_{s t}$ defined by the geometry of the node at the support (Fig. 1(a)), which is based on a model used by Collins and Mitchell (1991)

$$
w_{s t}=l_{b} \sin \theta+h_{a} \cos \theta
$$

where $l_{b}$ is the width of base plate, and $h_{a}$ is twice the distance between the centroid of the main reinforcement and the bottom of the beam. Because the expression adopted to calculate the width of the strut is based on the geometry of the node at the support, there are limits to its applicability. The definition of the width of the strut that was used would not be applicable in cases in which the main tension reinforcement is not properly anchored or distributed throughout the tie. The mode of failure of the beams used in the analysis was described by the respective authors as shear failure, so estimates of strength based on Eq. (4) are not applicable to failures due to yielding of the main tension reinforcement or to cases in which the mode of failure is due to bearing at the nodal zones.

The angle $\theta$ was approximated according to the following relationship

$$
\tan \theta \approx \frac{1}{a / d}=\frac{d}{a}
$$

Analysis of the test data considered in this study showed that the average ratio of the arc tangent of the $d / a$ ratio to the angle of the strut at failure was 1.05 with a coefficient of variation of $4 \%$. For the ideal condition, in which the strut is subjected to a uniaxial compressive stress field, the strength of the strut can be calculated as the product of the area of the strut and the compressive strength of concrete. For beams with a rectangular cross section, the nominal uniaxial strength of the strut $S_{\text {strut }}$ can be calculated based on Eq. (4) as

$$
S_{\text {strut }}=f_{c}^{\prime} A_{\text {strut }}=f_{c}^{\prime}\left(l_{b} \sin \theta+h_{a} \cos \theta\right) b
$$

where $b$ is the thickness of the web. A coefficient $C_{C}$ was obtained relating the nominal uniaxial strength of the strut $S_{\text {strut }}$ and the force $F$ applied at the support. Calculations were carried out using failure loads of beams without web reinforcement (a full list of the specimens and their respective references is given by Wong [2001]). This coefficient may be interpreted as an indicator of the relative contribution of the arch mechanism to the shear strength of deep beams. According to Eq. (6),

$$
C_{c}=\frac{F}{S_{\text {strut }}}=\frac{F}{f_{c}^{\prime}\left(l_{b} \sin \theta+h_{a} \cos \theta\right) b}
$$

Values of $C_{c}$, obtained by evaluating $F$ as the failure load of each specimen in Eq. (7), are shown in Fig. 4 with respect to the shear span-to-depth ratio. The following expression is proposed as a lower bound for the uniaxial strength parameter $C_{C}$ in terms of the shear span-to-depth ratio

$$
C_{c}=\frac{0.3}{a / d} \leq 0.85 \sin \theta
$$

The proposed expression for $C_{c}$ indicates that the contribution of the arch resistance mechanism decreases as the ald ratio increases, which is consistent with the observed behavior of deep and slender beams (de Pavia and Siess 1965; Smith and Vantsiotis 1982). An upper limit of 0.85 was set 
for $C_{c}$ as the ald ratio approaches zero because that condition resembles an unreinforced concrete block subjected to uniaxial compression.

\section{COMPARISON OF PROPOSED METHOD AND OTHER PROCEDURES TO ESTIMATE STRUT STRENGTH}

An approach that is commonly used for design (AASHTO 1998; ACI Committee 318 2002; CEB-FIP 1990) is to calculate the strength of the strut $S_{\text {strut }}$ as the product of a concrete strength coefficient for the strut $v$ and the compressive strength of the concrete (Alshegeir and Ramirez 1992). The strength coefficient for the strut accounts for the reduction in compressive strength that occurs because concrete is subjected to transverse tensile stresses and for differences between the simple stress field of the idealized model and the complex stress field that exists in the structural member. Several procedures have been proposed for calculating the magnitude of this coefficient; a summary of these expressions is presented by Alshegeir and Ramirez (1992). Expressions for $v$ proposed by Warwick and Foster (1993), the 2002 edition of the ACI 318 Code (ACI Committee 318 2002), and the AASHTO LRFD Bridge Code (AASHTO 1998), which is based on the modified compression field theory (Collins and Mitchell 1991), are presented and compared with the proposed model next.

Assuming that the strut has a uniform width, the mean compressive stress in the strut can be calculated as the force acting on the strut divided by its cross-sectional area. For beams with rectangular cross sections, the unit compressive stress in the strut can be calculated based on Eq. (1) and (4).

$$
\begin{gathered}
\sigma_{\text {strut }}=\frac{F_{\text {strut }}}{A_{\text {strut }}}=\frac{F}{w_{\text {st }} b \sin \theta} \\
=\frac{F}{\left(l_{b} \sin \theta+h_{a} \cos \theta\right) b \sin \theta}
\end{gathered}
$$

At failure, the value of the dimensionless coefficient $v$ can be calculated based on the shear strength, material, and geometric properties of beams without web reinforcement, as indicated by Eq. (10).

$$
\begin{gathered}
\mathrm{v}=\frac{F_{\text {strut }}}{S_{\text {strut }}}=\frac{\sigma_{\text {strut }}}{f_{c}^{\prime}} \\
=\frac{F}{\left(f_{c}^{\prime} l_{b} \sin \theta+h_{a} \cos \theta\right) b \sin \theta}=\frac{C_{c}}{\sin \theta}
\end{gathered}
$$

Based on Eq. (8) and (10), the following expression is proposed for the strut strength coefficient in deep beams

$$
v=\frac{0.3}{a / d \cdot \sin \theta} \leq 0.85
$$

Equation (11) can be solved for the limit case using Eq. (5). The 0.85 limit for $v$ controls for shear span-to-depth ratios smaller than 0.38 or angles of inclination for the strut greater than 70 degrees.
The 2002 edition of the ACI Building Code (ACI Committee 318 2002) includes a new appendix with provisions for design using strut-and-tie models. According to Appendix A of the 2002 ACI Building Code, the strength of struts should be taken as

$$
f_{c u}=0.85 \beta_{s} f_{c}^{\prime}
$$

where $\beta_{s}=0.75$ for bottle-shaped struts if the amount of web reinforcement provided is greater than the minimum specified in Section A.3.3, and $\beta_{s}=0.60 \lambda$ otherwise. For normalweight concrete, the factor $\lambda=1$, and according to Eq. (12), the compressive strength coefficient is

$$
v=0.85 \beta_{s}=\left\{\begin{aligned}
& 0.64 \text { if minimum reinforcement } \\
& \text { requirement is met } \\
& 0.51 \text { otherwise }
\end{aligned}\right.
$$

Warwick and Foster (1993) investigated the sensitivity of the compressive strength coefficient to four different parameters: concrete strength, shear span-to-depth ratio, vertical steel area, and horizontal steel area. They concluded that the strength of the strut was not very sensitive to the amount of reinforcement and proposed the following expression in terms of the remaining two parameters: compressive strength and shear span-to-depth ratio

$$
v=1.25-\frac{f_{c}^{\prime}}{500}-0.72\left(\frac{a}{d}\right)+0.18\left(\frac{a}{d}\right)^{2} \text { for } a / d \leq 2
$$

where $f_{c}^{\prime}$ is the compressive strength of the concrete in $\mathrm{MPa}$, and ald is the shear span-to-depth ratio. The expression is applicable in the range between 20 and $100 \mathrm{MPa}$.

The fourth expression presented for the compressive strength coefficient is that adopted by the AASHTO LRFD Bridge Design Specifications (AASHTO 1998) to calculate the compressive strength of struts,

$$
v=\frac{1}{0.8+170 \varepsilon_{1}}
$$

where $\varepsilon_{1}$ is the principal tensile strain in the concrete, which is approximated as

$$
\varepsilon_{1}=\varepsilon_{s}+\left(\varepsilon_{s}+0.002\right) / \tan ^{2} \theta
$$

where $\varepsilon_{s}$ is tensile strain in the ties, and $\theta$ is the angle between the tie and the strut. For the purpose of design, the AASHTO LRFD Code allows the adoption of $\varepsilon_{s}$ as the yield strain of the web reinforcement and requires a minimum amount of web reinforcement to limit the size of the cracks. Noting that $\tan \theta \approx d / a$, the compressive strength factor can be derived by substituting Eq. (16) into Eq. (15). Assuming that the yield strain and stress of the steel are 0.002 and $415 \mathrm{MPa}(60 \mathrm{ksi})$, respectively,

$$
v=\frac{1}{1.14+0.68(a / d)^{2}}
$$




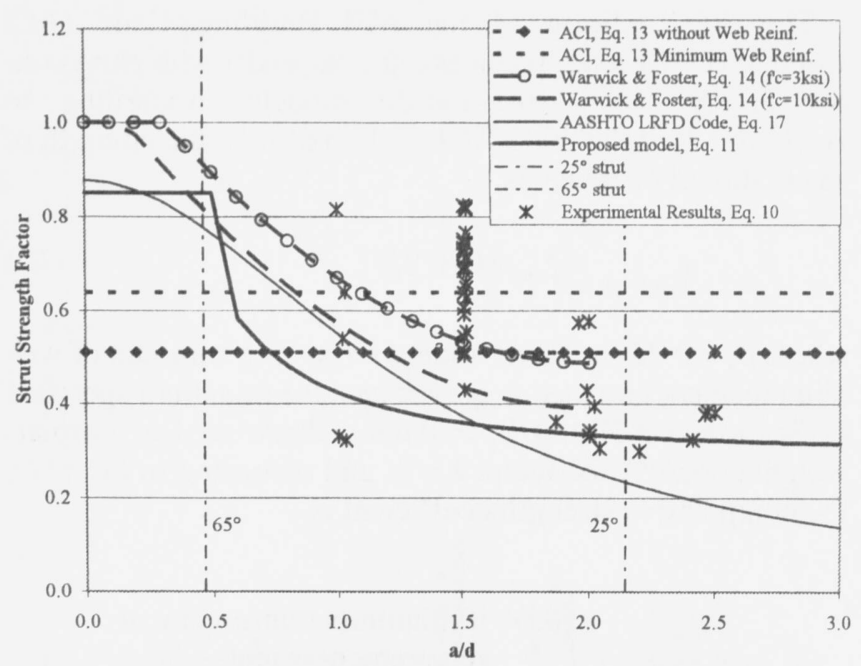

Fig. 5-Comparison of strut strength factor $v$ calculated according to different methods.

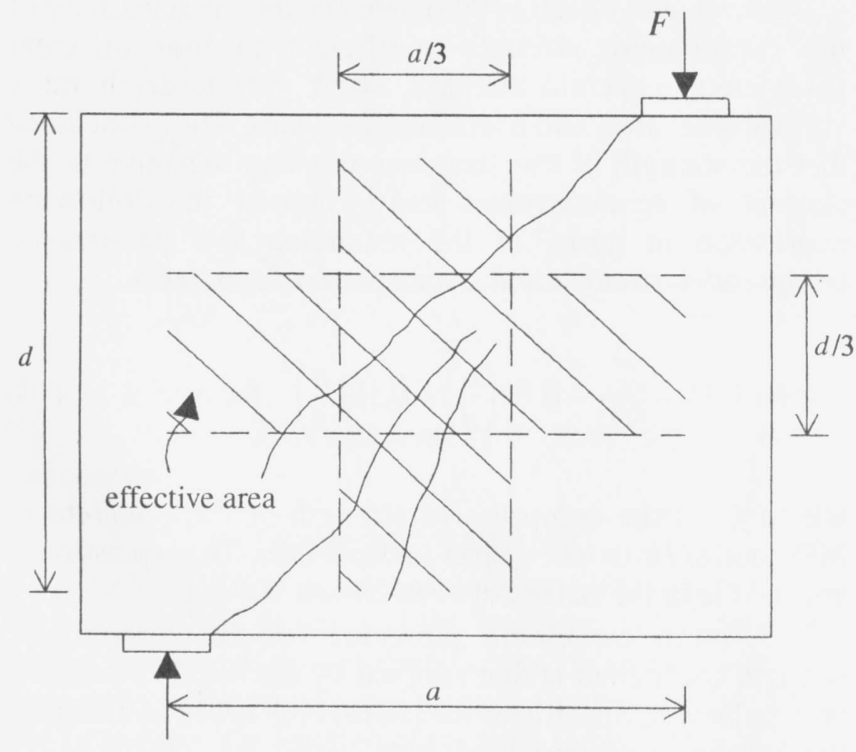

Fig. 6-Effective area for reinforcement.

Figure 5 shows a comparison between ACI 318 (ACI Committee 318 2002), the Warwick and Foster (1993) model, the AASHTO LRFD Code (AASHTO 1998) equation, and the proposed Eq. (11). The proposed equation was more conservative in the range of strut angles between 25 and 65 degrees (these values are presented as a reference because the ACI Code limits the angle between struts and ties to values greater than 25 degrees). The more conservative nature of the proposed equation can be attributed to test results with ald of approximately 1 , which had strength coefficients as low as 0.35 (Fig. 5). Similar coefficients were observed in specimens with vertical web reinforcement and steep strut angles (low ald), in which the strength of the specimen was primarily controlled by the strength of the strut. All methods presented, with the exception of Appendix A of the ACI Code (ACI Committee 318 2002), indicate that the compressive strength factor decreases as the angle of inclination of the strut decreases. As Fig. 5 shows, the coefficients of the ACI Code provided reasonable estimates of strength for angles of inclination for the strut as low as 30 degrees. If the strength reduction factor specified by the ACI Code for strut-and-tie models is considered $(\varphi=0.75)$, the magnitude of the strength coefficient drops to 0.48 or 0.38 , depending on whether the minimum web reinforcement requirement is provided. These values are close to the minimum observed for the test results that were analyzed.

\section{STRENGTH OF DEEP BEAMS WITH WEB REINFORCEMENT}

Two additional factors were derived correlating the total applied load with the nominal strength of the ties in the two remaining simple models (Fig. 1(c) and (d)). The total strength of the beam is calculated as the sum of the components attributed to each of the three basic load transfer mechanisms, represented by the forces in each of the main truss elements, multiplied by a correction coefficient

$$
V=C_{c} S_{s t r u t}+C_{w v} S_{t v}+C_{w h} S_{t h}
$$

An effective width for the ties of the two truss models shown in Fig. 1(c) and (d) was defined to quantify the contribution of distributed reinforcement to the total shear strength. Figure 6 shows a typical deep beam after cracking occurs. Strains near the support and the load point are small, reducing the effectiveness of reinforcement. Furthermore, the strut-and-tie models in Fig. 1(c) and (d) have the horizontal and vertical ties located at the center of the shear span and depth of the beam. For those reasons, only the reinforcement placed in the vicinity of the ties was taken into consideration. and the effective widths for the vertical and horizontal ties were defined as $a / 3$ and $d / 3$, respectively. The contribution of the reinforcement outside these two bands was neglected. According to the proposed model, the nominal strength of each truss element is expressed as

$$
\begin{gathered}
S_{s t r u t}=f_{c}^{\prime} b w_{s t} \\
S_{t v}=A_{t v} f_{y v}=\rho_{w v} b \frac{a}{3} f_{y v}
\end{gathered}
$$

$$
S_{t h}=A_{t h} f_{y h}=\rho_{w h} b \frac{d}{3} f_{y h}
$$

where $f_{c}^{\prime}$ is the compressive strength of concrete; $b$ is the thickness of the beam; $\rho_{w v}$ and $\rho_{w h}$ are the vertical and horizontal reinforcement ratios, respectively; $A_{t v}$ and $A_{t h}$ are the areas of the vertical and horizontal ties falling within the effective widths, respectively; and $f_{y v}$ and $f_{y h}$ are the yield strengths of the vertical and horizontal reinforcement, respectively.

According to Eq. (18), the contribution of the strut is the product of the strength parameter $C_{c}$ and the nominal strength of the strut given by Eq. (19). The value of $C_{C}$ proposed in Eq. (8) was adopted, and the remaining experimental results were used to calibrate the two remaining coefficients. The data bank consisted of a total of 175 reinforced concrete deep beams with various reinforcement configurations. A detailed listing of the experimental results that were used in the analysis and their respective references is presented by Wong (2001). Concrete strength ranged from 14 to $73 \mathrm{MPa}$ ( 2.0 to $10.6 \mathrm{ksi}$ ) and the a/d ratio ranged from 0.35 to 2.50 . The next step consisted of developing expressions for the coefficients $C_{w v}$ and $C_{w h}$ in terms of ald. 
Table 1-Mean ratio of experimental to estimated strength

\begin{tabular}{c|c|c|c|c|c|c}
\hline \multirow{2}{*}{$\begin{array}{c}\text { Type of distributed } \\
\text { reinforcement }\end{array}$} & Unreinforced & Vertical & Horizontal & $\begin{array}{c}\text { Horizontal and } \\
\text { vertical }\end{array}$ & Overall & $\begin{array}{c}\text { Overall, AIJ } \\
\text { guideline }\end{array}$ \\
\cline { 2 - 7 } & \multicolumn{7}{|c|}{$V_{\text {test }} / V_{\text {calculated }}$} \\
\hline Number of specimens & 45 & 76 & 1 & 53 & 175 & 175 \\
\hline Average & 1.60 & 1.26 & 1.27 & 1.45 & 1.40 & 1.07 \\
\hline Standard deviation & 0.44 & 0.20 & - & 0.18 & 0.31 & 0.20 \\
\hline Maximum & 2.29 & 1.94 & - & 1.84 & 2.29 & 1.62 \\
\hline Minimum & 0.77 & 0.78 & - & 1.03 & 0.77 & 0.57 \\
\hline Coefficient of variation & 0.28 & 0.16 & - & 0.12 & 0.22 & 0.19 \\
\hline
\end{tabular}

\section{STRENGTH OF SPECIMENS WITH VERTICAL REINFORCEMENT}

Test results for a subset of beams having only vertical web reinforcement were analyzed to calibrate the coefficient $C_{w v}$. It was assumed that in these specimens the shear force was carried by the combined action of the strut and the truss mechanism that includes a vertical tie (Fig. 2(c)). Substituting $S_{t h}$ equal to zero in Eq. (18) and solving for the coefficient $C_{w v}$,

$$
C_{w v}=\frac{V-C_{c} S_{s t r u t}}{S_{t v}}
$$

where $S_{\text {strut }}$ and $S_{t v}$ are given by Eq. (19) and (20), and $V$ is the measured strength of the beam. Values of $C_{w v}$ calculated from the subset of beams without horizontal web reinforcement are shown Fig. 4. Given the high degree of scatter in the data, particularly for low values of $a / d$, and the trend exhibited by $F_{\text {truss } 1}$ in Fig. 2 (Eq. (2)), a constant value of unity was adopted as a lower bound for $C_{w v}$

$$
C_{w v}=1
$$

At very steep angles of inclination for the strut ( $a / d$ close to zero), it is expected that the vertical reinforcement will be subjected to compression and still carry a fraction of the total force proportional to the amount of reinforcement provided.

\section{STRENGTH OF SPECIMENS WITH DISTRIBUTED HORIZONTAL AND VERTICAL REINFORCEMENT}

Similarly, the subset of beams with vertical and horizontal reinforcement were used to calibrate the parameter $C_{w h}$. Equation (18) was solved for the parameter $C_{w h}$ and proposed expressions for $C_{c}$ and $C_{w v}$ (Eq. (8) and (23), respectively) were used to account for the contribution of the strut and the vertical reinforcement.

$$
C_{w h}=\frac{V-C_{c} S_{s t r u t}-C_{w v} S_{t v}}{S_{t h}}
$$

The calculated values for $C_{w h}$ are shown in Fig. 4. Past research indicates that the effect of the horizontal reinforcement decreases as a/d increases (Rogowsky, MacGregor, and Ong 1986; Smith and Vantsiotis 1982; Warwick and Foster 1993). The trend is reflected in the data in Fig. 4. Consequently, an expression in which the coefficient $C_{w h}$ was limited to zero for ald greater than unity was proposed as a lower bound

$$
C_{w h}=3\left(1-\frac{a}{d}\right) \geq 0
$$

\section{SHEAR STRENGTH ACCORDING TO JAPANESE DESIGN GUIDELINE}

The results of the proposed model were compared with those from a design guideline by the Architectural Institute of Japan (AIJ) (Aoyama 1993). Although this is not strictly a strut-and-tie approach, it was selected for comparison because it assumes that the total shear capacity consists of components associated with a truss mechanism and an arch mechanism. The total shear strength is obtained by adding the component associated with the arch and truss mechanisms

$$
\begin{gathered}
V_{u}=V_{T}+V_{a}=b j_{t} \rho_{w} \sigma_{w y} \cot \phi+ \\
b \frac{D}{2}(1-\beta) v_{0} \sigma_{B} \tan \theta
\end{gathered}
$$

where $\beta=\frac{\rho_{w} \sigma_{w y}}{v_{0} \sigma_{B}}\left(1+\cot ^{2} \theta\right) ; v=0.7-\sigma_{B} / 195\left(\sigma_{B}\right.$ in $\left.\mathrm{MPa}\right)$; $\rho_{w} f_{w y} \geq v \sigma_{B} / 2 ;$ and $f_{w y} \leq 25 \sigma_{B}$.

The value of $\cot \phi$ is the largest value within the range of

$$
\cot \phi \leq\left\{\begin{array}{c}
2 \\
\sqrt{\frac{v_{0} \sigma_{B}}{\rho_{w} \sigma_{w y}}-1} \\
\frac{j_{t}}{D \tan \theta}
\end{array}\right\}
$$

In Eq. (26) and (27), $j_{t}$ is the distance between centroids of axial reinforcement; $\rho_{w}$ is web reinforcement ratio; $\sigma_{w y}$ is the yield strength of web reinforcement; $\phi$ is the angle of the struts in the truss mechanism; $D$ is the depth of the beam; $v_{0}$ is the strength reduction factor for the strut; $\sigma_{B}$ is the cylinder strength of concrete, in $\mathrm{MPa} ; \beta$ is the fraction of the total force in the strut assigned to the truss mechanism; and $\theta$ is the angle of inclination of the arch with respect to the specimen. For simplification, the model assumes that the angle of inclination of the struts in the truss and arch mechanism are equal.

\section{ANALYSIS OF RESULTS}

Figure 7 shows the ratio of measured-to-calculated strength with respect to the $a / d$ for all beams in the database, 


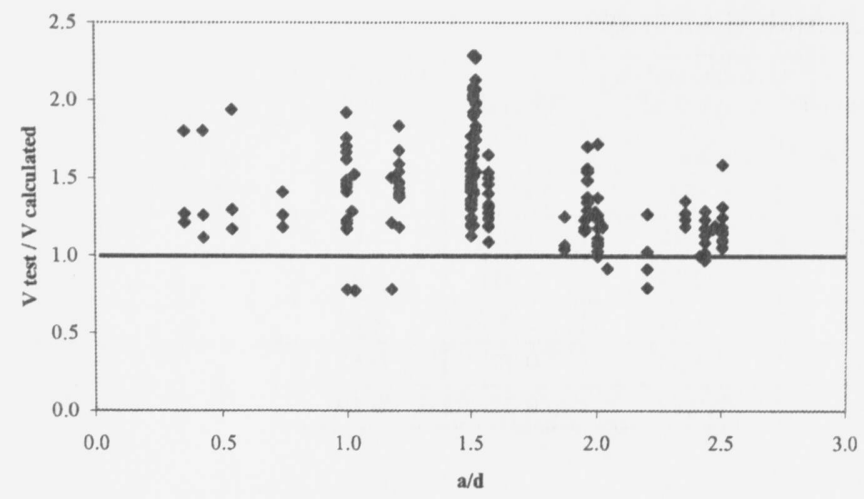

Fig. 7-Ratio of measured-to-calculated strength versus shear span-to-depth ratio according to proposed equations.

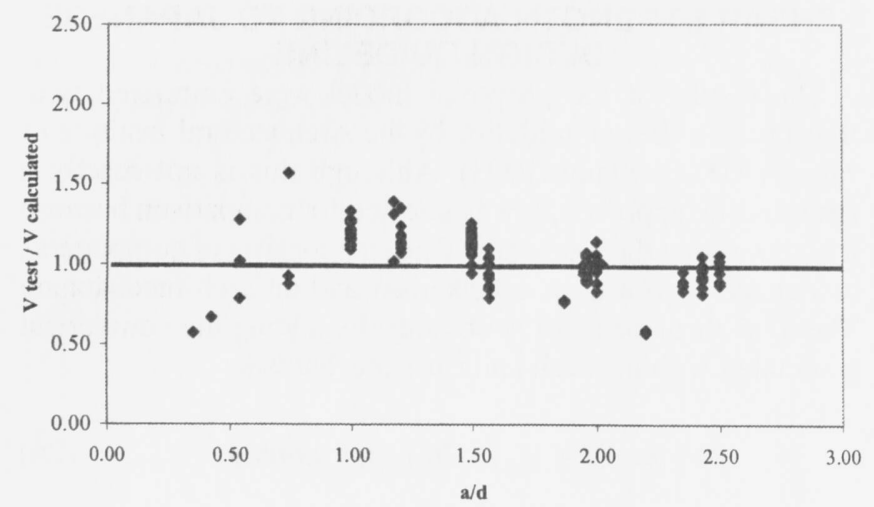

Fig. 8-Ratio of measured-to-calculated strength versus shear span-to-depth ratio using AIJ guidelines (Aoyama 1993).

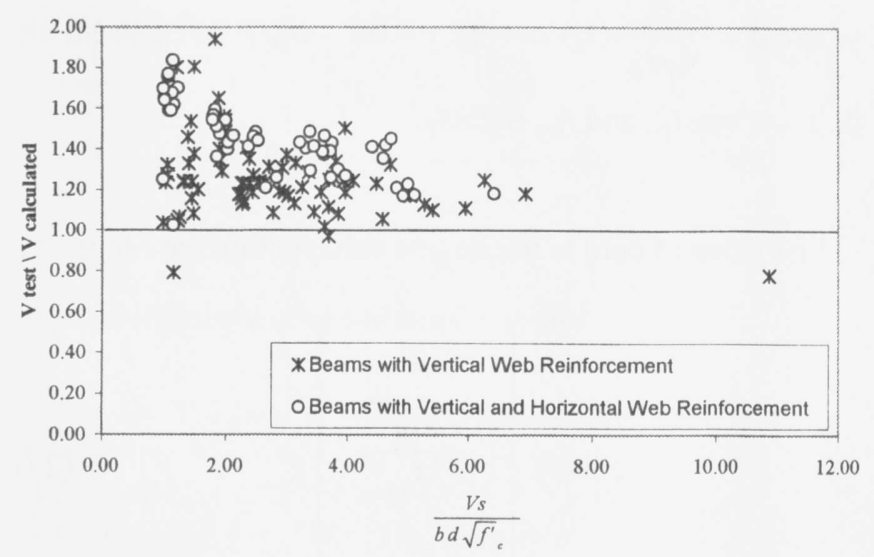

Fig. 9-Ratio of measured-to-calculated shear strength versus shear stress carried by reinforcement according to proposed equations.

according to the proposed model. Table 1 summarizes the statistical results for concrete specimens with different reinforcement configurations, including the results obtained with the AIJ guideline. Table 1 indicates that for the proposed model, the scatter of results was larger in the case of specimens without web reinforcement. The coefficient of variation was significantly lower for specimens that had any type of web reinforcement, and no test results were underestimated for beams with both horizontal and vertical web reinforcement. The proposed model resulted in a mean ratio of measured-to-calculated strength of 1.40 and a standard deviation of 0.31 , with a coefficient of variation of 0.22 .

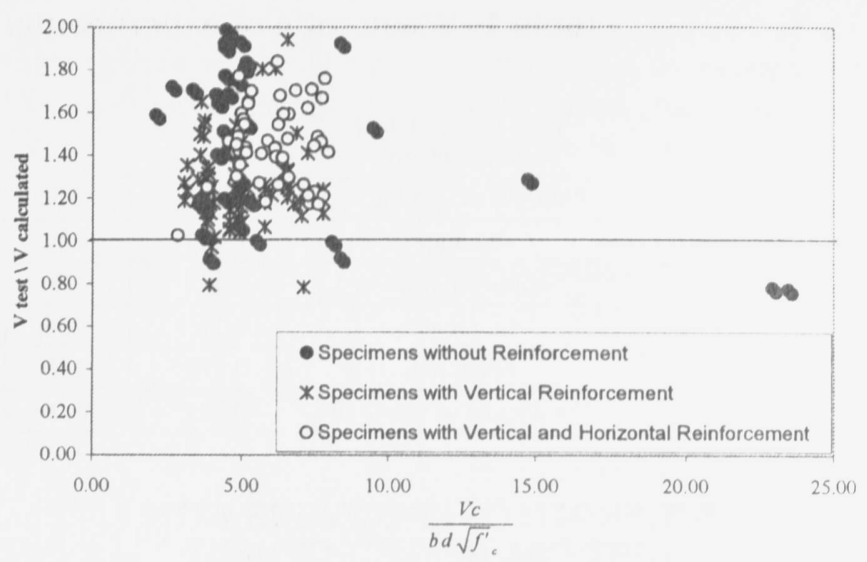

Fig. 10-Ratio of measured-to-calculated shear strength versus shear stress carried by concrete according to proposed equations.

The AIJ guideline (Fig. 8), which had a mean ratio of measured-to-calculated strength of 1.07 and a standard deviation of 0.20 , provided a better estimate of the mean strength. The lower mean obtained with the AIJ guideline, which corresponds to approximately one standard deviation below the proposed model, is attributed to the fact that the proposed equations were developed to provide a lower-bound estimate of strength. A comparison between the coefficients of variation obtained with the two approaches -0.22 for the proposed model and 0.19 for the AIJ guideline-indicate that the accuracy was similar for the set of data that was investigated.

The formulation used in the AIJ guideline indicates that the compressive stress acting on the strut of the truss mechanism must be smaller than or equal to the effective strength of the concrete in the web, and any remaining capacity is taken by the arch mechanism. This establishes an effective upper limit on the amount of vertical reinforcement that can be placed in the web, which depends on the strength of the concrete. According to the proposed model, any reduction in the strength of the strut related to the amount of web reinforcement is reflected by the coefficients for the horizontal and vertical truss mechanisms. Warwick and Foster (1993) concluded in their research that the amount of web reinforcement did not have a significant effect on the strength of the strut, and their proposed equation for the strut strength factor $v$ depends only on the compressive strength of concrete and the shear span-to-depth ratio of the beam. Figure 9 and 10 show the relationship between the ratio of measured-to-calculated strength and the mean shear stress attributed to plain concrete and web reinforcement, according to the proposed model. In the majority of the beams that were analyzed, the unit shear stresses attributed to the web reinforcement ranged from 0 to $8 \sqrt{ } f_{c}^{\prime}$ (in units of psi). The measured strength was not underestimated in any of the specimens in which the unit shear stresses attributed to the shear reinforcement ranged between 4 and $8 \sqrt{ } f_{c}^{\prime}$. Figure 10 shows that in the majority of the data the unit shear stress carried by the concrete ranged between 2 and $10 \sqrt{ } f_{c}^{\prime}$.

Figure 11 shows the ratio of measured-to-calculated strength versus the percentage of web reinforcement of the specimens in the database. The figure shows that a wide range was represented by the set of data-between 0.15 and $3.5 \%$.

The amount of reinforcement calculated using Eq. (22) and (24) was compared with that required by the strut-andtie models shown in Fig. 1(c) and 3, which may not represent 
the best choice in some instances, but are acceptable models according to the ACI Code (ACI Committee 318 2002). The ratio of shear force in the vertical tie according to each of the two strut-and-tie models to the force calculated with Eq. (22) is shown Fig. 11, for the subset of specimens with only vertical web reinforcement. The amount of vertical reinforcement required by the combined strut-and-tie model (Fig. 3) was similar to that required by the proposed equations for ald greater than 1.5 (Fig. 12). In specimens that had span-todepth ratios less than 1.5 , the combined model resulted in a smaller amount of vertical reinforcement. A similar comparison with the vertical truss model (Fig. 1(c)) shows that it required approximately twice the amount of reinforcement than the proposed equations.

In the case of horizontal web reinforcement, the comparison was limited to only four test specimens because the proposed equations suggest neglecting the effect of the horizontal reinforcement when ald is greater than 1. A comparison of the amount of reinforcement required by the two strut-andtie models and the proposed showed that the amount of reinforcement required by the combined model is slightly less but comparable with that required by the proposed equations. The simple strut-and-tie model (Fig. 1(d)) also required approximately $50 \%$ more reinforcement than the proposed equations in this case, although it is important to point out that this particular truss model neglected the contribution of the vertical reinforcement.

\section{SUMMARY AND CONCLUSIONS}

This investigation focused on developing a relationship between the strength of deep beams and the forces in the main strut and ties of models representing the load carried by plain concrete, vertical, and horizontal web reinforcement. According to the proposed model, the total shear strength is given by

$$
V=\frac{0.3}{a / d} f_{c}^{\prime} b w_{s t}+A_{t v} f_{y v}+3(1-a / d) A_{t h} f_{y h}
$$

where $\tan \theta \approx 1 /($ ald $)$, and the width $w_{s t}$ of the strut is calculated according to Eq. (4). The following limits apply to Eq. (28): the term $0.3 /(a / d)$ has an upper limit of $0.85 \sin \theta$, and the term $(1-a / d)$ has a lower limit of 0 .

The ratio of calculated force to nominal strength of the strut, designated concrete strength coefficient $v$, was compared with the new strut-and-tie provisions of the ACI 318-2002 Code (ACI Committee 318 2002), equations proposed by Warwick and Foster (1993), and AASHTO LRFD Bridge Code (AASHTO 1998). Safety was the primary concern considered in the formulation of the proposed equation, which resulted in a conservative estimate of the strength in beams with strut inclination angles ranging between 30 and 60 degrees (shear span-to-depth ratios ranging between approximately 0.5 and 1.5 ). Results indicated that the strut factor $v$ decreased as the angle of inclination of the strut decreased.

Estimates of shear strength according to the proposed model were compared with estimates according to a guideline by the AIJ (Aoyama 1993). The accuracy of the AIJ guideline for the entire group of specimens was comparable to that of the proposed equations (coefficient of variation of 0.19 for the AIJ guideline compared with 0.22 for the proposed equations). The proposed equations provided safer

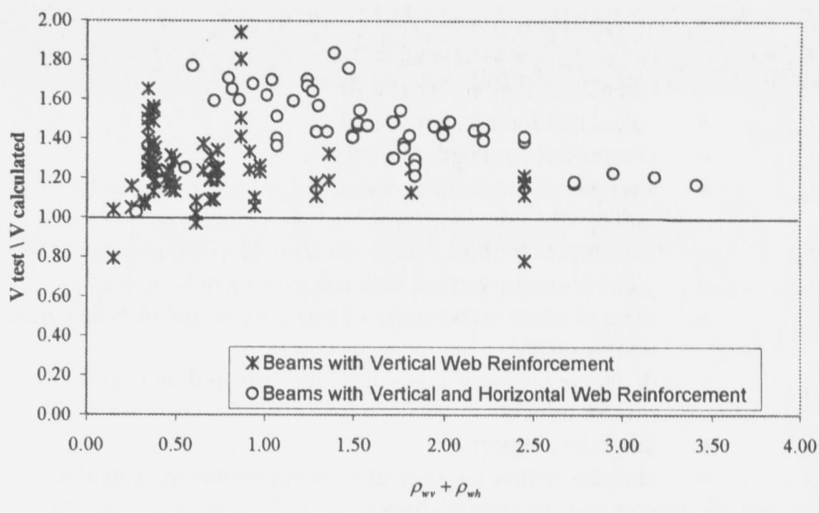

Fig. 11-Ratio of measured-to-calculated shear strength versus web reinforcement ratio for all specimens considered.

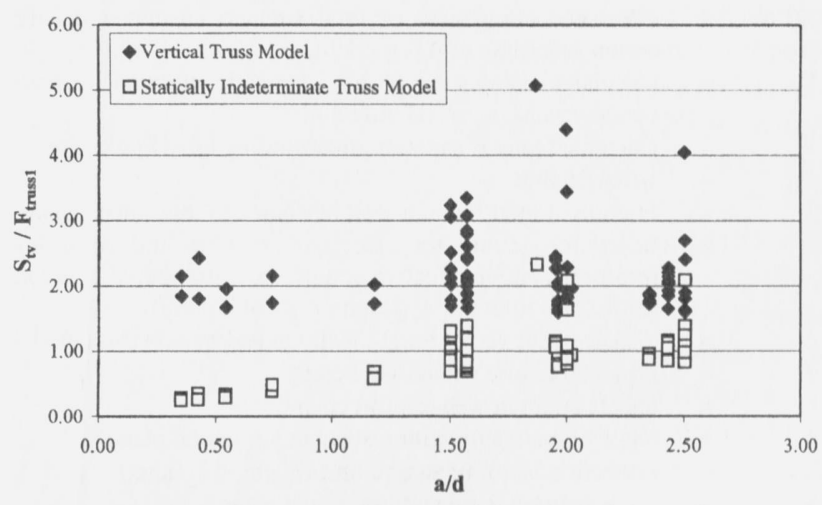

Fig. 12-Comparison of calculated amount of vertical reinforcement.

estimates of strength for beams with shear span-to-depth ratios of less than 1 .

A comparison of the amount of reinforcement required by four different strut-and-tie models showed that the amount of reinforcement required by a statically indeterminate model (Fig. 3) was closest to the proposed equations, indicating that the assumption of equal modulus of elasticity and crosssectional area for all members was adequate for design purposes. The two simple strut-and-tie models analyzed in this paper (Fig. 1(c) and (d)) were found to require approximately double the amount of reinforcement required by the proposed equations (Wong 2001), which indicates that, although their use leads to safe designs, the results are very conservative.

\section{ACKNOWLEDGMENTS}

The authors would like to acknowledge Steve McCabe, David Darwin, and JoAnn Browning of the Department of Civil Engineering at the University of Kansas for their valuable comments and contributions for the development of this work.

\section{NOTATION}

$A_{\text {strut }}=$ cross-sectional area of compressive strut

$A_{\text {th }}=$ area of horizontal tie

$A_{t v} \quad=\quad$ area of vertical tie

$a=$ shear span, distance between center of load to center of reaction

$b \quad=$ width of beam

$C_{c} \quad=\quad$ correction factor for calculated force in strut

$C_{w h}=$ correction factor for calculated force in horizontal tie

$C_{w v}=$ correction factor for force calculated in vertical tie

$D \quad=$ total depth of beam

$d \quad=$ effective depth of beam 
= calculated force in strut

$=$ calculated force in vertical tie

calculated force in horizontal tie

compressive strength of concrete

$=$ strength of concrete in struts according to Appendix $\mathrm{A}$ of 2002 ACI Code

= yield stress for horizontal web reinforcement in beam

yield stress for vertical web reinforcement in beam

$=$ twice distance from bottom of beam to centroid of main tensile reinforcement

distance between centroids for top and bottom tensile reinforcement

$=$ length of support

= stiffness matrix for statically indeterminate truss model

$=$ nominal strength of struts

$=$ nominal strength of horizontal tie

nominal strength of vertical tie

$=$ calculated shear strength of beam according to proposed model

$=$ calculated component of total strength attributed to arch action according to AIJ guideline

$=$ calculated component of total strength attributed to truss action according to AIJ guideline

$=$ calculated total shear strength according to AIJ guideline width of strut

fraction of total force in strut attributed to truss mechanism

factor to account for effect of cracking and confining reinforcement on effective compressive strength of concrete in strut according to Appendix A of ACI 318-02

displacement vector for statically indeterminate truss model principal tensile strain in concrete

tensile strain in web reinforcement

angle of main strut with respect to horizontal plane

correction factor related to unit weight of concrete

angle between strut and horizontal plane

effective compressive strength factor for concrete in strut effective compressive strength factor for concrete in strut reinforcement ratio for vertical web reinforcement reinforcement ratio for horizontal web reinforcement reinforcement ratio for vertical web reinforcement compressive strength of concrete, in MPa (cylinder strength) mean compressive stress acting on strut tensile strength of web reinforcement
AASHTO, 1998, “AASHTO LRFD Bridge Design Specifications," American Association of State Highway and Transportation Officials, Washington, D.C.

ACI Committee 318, 2002, "Building Code Requirements for Structural Concrete (ACI 318-02) and Commentary (318R-02)," American Concrete Institute, Farmington Hills, Mich., 443 pp.

Alshegeir, A., and Ramirez, J. A., 1992, "Strut-Tie Approach in Pretensioned Beams," ACI Structural Journal, V. 89, No. 3, May-June, pp. 296-304

Aoyama, H., 1993, "Design Philosophy for Shear in Earthquake Resistance in Japan," Earthquake Resistance of Reinforced Concrete Structures-A Volume Honoring Hiroyuki Aoyama, University of Tokyo Press, Tokyo, Japan, pp. 407-418.

CEB-FIP, 1990, "CEB-FIP Model Code for Concrete Structures," Comite Euro-International du Beton/Federation Internationale de la Precontrainte, Paris.

Collins, M., and Mitchell, D., 1991, Prestressed Concrete Structures, Prentice Hall, Upper Saddle River, N.J., 766 pp.

de Paiva, H. A. R., and Siess, C. P., 1965, "Strength and Behavior of Deep Beams in Shear," Journal of Structural Engineering, ASCE, V. 91 , No. ST5.

Foster, S. J., and Gilbert, R. I., 1998, "Experimental Studies on HighStrength Concrete Deep Beams," ACI Structural Journal, V. 95, No. 4 July-Aug., pp. 382-390.

Ricketts, D. R., and MacGregor, J. G., 1985, “Ultimate Behaviour of Continuous Deep Reinforced Concrete Beams," MS thesis, Department of Civil Engineering, University of Alberta, Canada, 90 pp

Rogowsky, D. M., and MacGregor, J. G., 1983, "Shear Strength of Deep Reinforced Concrete Continuous Beams," Structural Engineering Report 110, Department of Civil Engineering, University of Alberta, Canada, 178 pp.

Rogowsky, D. M.; MacGregor, J. G.; and Ong, S. Y., 1986, "Tests of Reinforced Concrete Deep Beams.” ACI Journal, Proceedings V. 83, No. 4. July-Aug., pp. 614-623

Smith, K. N., and Vantsiotis, A. S., 1982, "Shear Strength of Deep Beams,” ACI Journal, Proceedings V. 79, No. 3, May-June, pp. 201-213.

Warwick, W. B., and Foster, S. J., 1993, "Investigation Into the Efficiency Factor Used in Non-Flexural Reinforced Concrete Member Design," UNICIV Report No. R-320, School of Civil Engineering, University of New South Wales, Kensington, $81 \mathrm{pp}$.

Wong, K. H., 2001, "Design of Reinforced Concrete Beams Using Strutand-Tie Models," MS thesis, Department of Civil and Environmental Engineering, University of Kansas, Lawrence, Kans., July, 68 pp. 